\title{
Tritium Reduction and Control in the Vacuum Vessel During TFTR Outage and Decommissioning*
}

\author{
W. Blanchard, ${ }^{a}$ R. Camp, ${ }^{a}$ H. Carnevale, ${ }^{a}$ M. Casey, ${ }^{b}$ J. Collins, ${ }^{a}$ C. A. Gentile, ${ }^{a}$ M. Gibson, ${ }^{b}$ \\ J. C. Hosea, ${ }^{a}$ M. Kalish, ${ }^{a}$ J. Langford, ${ }^{b}$ S. Langish, ${ }^{b}$ D. Miller, ${ }^{a}$ \\ A. Nagy, ${ }^{a}$ G. G. Pearson, ${ }^{a}$ R. Raucci, ${ }^{b}$ K. Rule, ${ }^{a}$ J. Winston ${ }^{a}$ \\ aPrinceton Plasma Physics Laboratory, Princeton University \\ Princeton, New Jersey 08543 \\ $\mathrm{b}_{\text {General Physics Corporation }}$ \\ Columbia, Maryland 21046
}

\begin{abstract}
In the summer/fall of 1996 after nearly three years of D-T operations, TFTR underwent an extended outage during which large port covers were removed from the vacuum vessel in order to complete upgrades to the tokamak. Following the venting of the torus, a three tier system was developed for the outage in order to reduce and control the free tritium in the vacuum vessel so as to minimize the exposure to personnel during port cover removal and reinstallation. The first phase of the program to reduce the free tritium consisted of direct flowthrough of room air through the vacuum vessel to the molecular sieve beds using the Torus Cleanup System. Real time measurements of the effluent tritium concentration were used to derive the amount of tritium removed from the torus. Once the free tritium in the vessel had been reduced to approximately $50 \mathrm{Ci}$, a second phase was initiated using a 55 Gallon Drum Bubbler System for the direct processing of the vacuum vessel to further lower the tritium level in the torus. Tritium oxide is absorbed by the bubbler system with the exhaust vented to one of the tritium monitored HVAC ventilation stacks. To preclude the release of tritium to the Test Cell location of TFTR and to minimize the exposure of workers, a variable flow exhaust system was employed in order to maintain a negative pressure in the vacuum vessel between $0.05 "$ and $1.5^{\prime \prime}$ w.c. during the removal of port covers ranging in size from approximately 5 to 1000 in $^{2}$. These systems were completely successful in reducing and controlling the free tritium in TFTR and were instrumental in maintaining ALARA (As Low As Reasonably Achievable) exposures to tritium during the 1996 outage. These systems are again being utilized during the safe shutdown and decommissioning of TFTR which commenced in April of 1997. This paper describes in detail the configuration of these systems and the data obtained during the outage and safe shutdown of TFTR.
\end{abstract}

\section{INTRODUCTION}

TFTR is the first magnetic fusion experimental facility to use significant quantities of tritium. During the D-T phase of TFTR greater than 49,000 Ci of tritium were injected into the torus either with gas puffs or with energetic neutral beams. In 1996 the decision was made to make significant upgrades to the tokamak, primarily in ICRF auxiliary heating systems, diagnostics and tritium gas injection systems. In the execution of these upgrades it was necessary to vent the vacuum vessel and remove port covers to gain access to the interior of the torus. Safety considerations were the primary concerns for these activities and the reduction and control of the free tritium in the vacuum vessel atmosphere was essential for achieving ALARA in personnel exposure. Prior to each of the vacuum vessel openings, a number of tritium removal techniques were employed to remove significant quantities of tritium held in the surface layer of the graphite limiters (approximately $2000 \mathrm{lbs}$ and $20 \mathrm{~m}^{2}$ area). These techniques included pulse discharge cleaning (PDC), glow discharge cleaning (GDC) with deuterium and a helium/oxygen mixture and vacuum vessel bakeout under vacuum and while vented with air from the Test Cell ${ }^{1}$ ( one million $\mathrm{ft}^{3}$ room that houses TFTR). When these activities were completed it was necessary to maintain the free tritium level at a low level prior to port cover removal in a cost effective manner. The first technique used was a continuous air purge of the vacuum vessel processed to molecular sieve beds using the Torus Cleanup System (TCS) configured for once through operation. The Torus Cleanup System was used until the tritium concentration was reduced in the radioactive waste stream to a level at which its use was no longer warranted. Also the TCS was required for a number of other tasks and was not generally available for continuous use during the outage or shutdown periods. Therefore a dedicated drum bubbler system was installed on the torus to further reduce the tritium by scrubbing the tritium oxide (HTO) as room air was permitted to flow through the vacuum vessel.

The principal upgrade in the 1996 Outage was the installation of three RF antennas which required the removal of large port covers $\left(\sim 1000 \mathrm{in}^{2}\right)$. Concurrently a number of other improvements were made to diagnostics on the tokamak. Windows $\left(\sim 5\right.$ in $\left.^{2}\right)$ located at the bottom of the machine were removed so that they could be cleaned of carbon dust that had accumulated on them from the years of

\footnotetext{
* This work supported by U.S. DoE Contract No. DE-AC02-76-CHO-3073
} 
operation with graphite limiters in the tokamak. Because the carbon dust had appreciable tritium contamination, special handling was required. To accommodate this wide variety of tasks, a variable flow HVAC system was installed on the torus that was capable of controlling the negative pressure in the vacuum vessel between -1.5 " w.c. and -0.05 " w.c.

\section{Torus Cleanup System}

After the bulk of the tritium on the interior surfaces of TFTR had been removed by active cleaning methods such as bakeout, PDC and GDC, the torus was repeatedly vented/pumped followed by a longer period of purging with a continuous flow of Test Cell air using the Torus Cleanup System to collect the tritium in the form of tritiated water. During TFTR operations prior to the vent, a normal cleanup cycle was comprised of first pumping the effluent from the vacuum vessel or from the warmed cryo panels in the Neutral Beam enclosures to holding tanks in the Tritium Area using the torus and neutral beam vacuum pumps. The holding tanks were then processed in a batch mode through the TCS which oxidizes the tritium (HTO) and delivers the tritiated water vapor to molecular sieve beds. The molecular sieve beds absorb the water vapor out of the effluent stream which is then stacked. In the holding tanks the tritium content is measured with an ion chamber and PVT measurements ${ }^{2}$. For direct processing of the vacuum vessel at near atmospheric pressure this arrangement was modified. A line was installed in the pump duct of TFTR bypassing the vacuum pumps and directing the effluent directly to the holding tanks (Fig. 1). Two small pumps connected to the holding tanks in the Tritium Area were used for drawing the air through the torus at a flow rate of approximately $4 \mathrm{cfm}$. A metered flow valve was inserted in series with an inlet valve to the vacuum vessel, and adjusted to maintain a constant pressure in the torus (nominally 600 Torr) and a constant flow rate through the holding tanks. The exhaust of the holding tank pumps fed directly into the intake of the TCS system and the tritium was processed in the usual manner. Because the tritium level in the vessel and holding tank changed slowly with time, the concentration could be measured once per hour with the ion chamber. The amount of air flowing through the holding tank was simply derived from the pumping speed at a constant pressure and this value was multiplied by the concentration to determine the amount of tritium deposited on the molecular sieve beds each hour. The tritium monitor in the HVAC stack was cross referenced to grab sample bubbler measurements and against the holding tank ionization chambers at higher concentrations of tritium. At lower tritium concentrations the stack tritium monitor was used to track the relative background level for the ionization monitors.

During the 1996 Outage the TCS was used in this configuration with air flowing through the vacuum vessel at room temperature for about 150 hours. Approximately 350 $\mathrm{Ci}$ of tritium were removed from the vacuum vessel in this period. During the safe shutdown phase of TFTR, the torus was processed at $150^{\circ} \mathrm{C}$ for 42 hours and more than $400 \mathrm{Ci}$ of tritium were removed from the machine. Because the
TCS system is required for a number of tasks, it could not be dedicated to the torus indefinitely and the vacuum vessel processing was switched over to the Drum Bubbler System when the free tritium content in the vessel was approximately $50 \mathrm{Ci}$ during the 1996 Outage and $20 \mathrm{Ci}$ during the safe shutdown phase of TFTR.

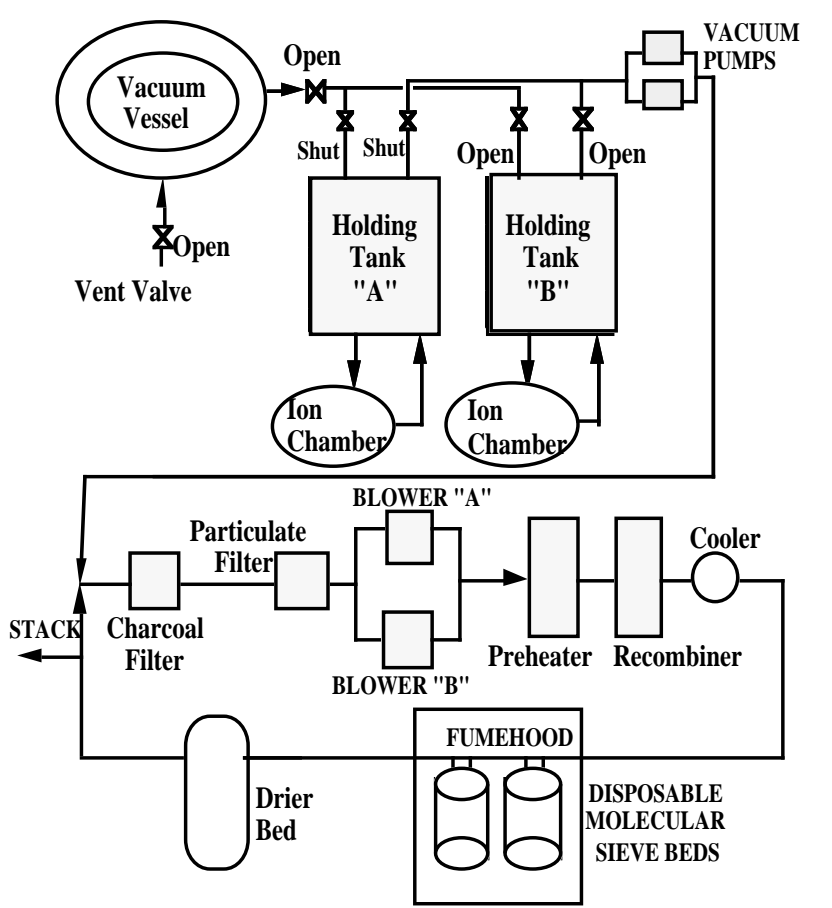

Fig. 1. Diagram of the direct processing loop used with the Torus Cleanup System. In the illustration both the inlet and outlet valves to Holding Tank "B" are open allowing for a continuous flow through the system. The ion chambers were used to make real time measurements of the tritium concentrations to derive the tritium removed from the vacuum vessel.

\section{Drum Bubbler System}

The Drum Bubbler System was designed to reduce the tritium concentration of the vacuum vessel atmosphere over an extended period of time. The main components of the system are: a 55 gallon drum that is approximately two thirds full of water and is connected to the end of one of the torus pump ducts, a dual piston pump connected to the outlet of the drum, and a dryer (condenser) in the exhaust line of the pump (Fig. 2). In operation, the pump pulls a partial vacuum over the surface of the water and draws air from the vacuum vessel through the water in the drum and tritium oxide is scrubbed out of the air stream. The drum is equipped with an aeration system located at the bottom of the drum to enhance the removal of tritium oxide ${ }^{3}$. The exhaust of the pump contains moisture which the dryer condenses out and returns to the drum. The exhaust is then either vented through the facility stack in an open loop configuration or returned to the vacuum vessel in a closed loop. In the open loop configuration the metered flow valve at the inlet of the vacuum vessel was adjusted to maintain a constant pressure in the torus similar to the TCS configuration $(\sim 4 \mathrm{cfm})$. During the 1996 Outage, the 
Drum Bubbler System was found to have a reduction factor for tritium of greater than $90 \%$. During the safe shutdown of TFTR the system is being used in the closed loop configuration with no tritium being released up the stack.

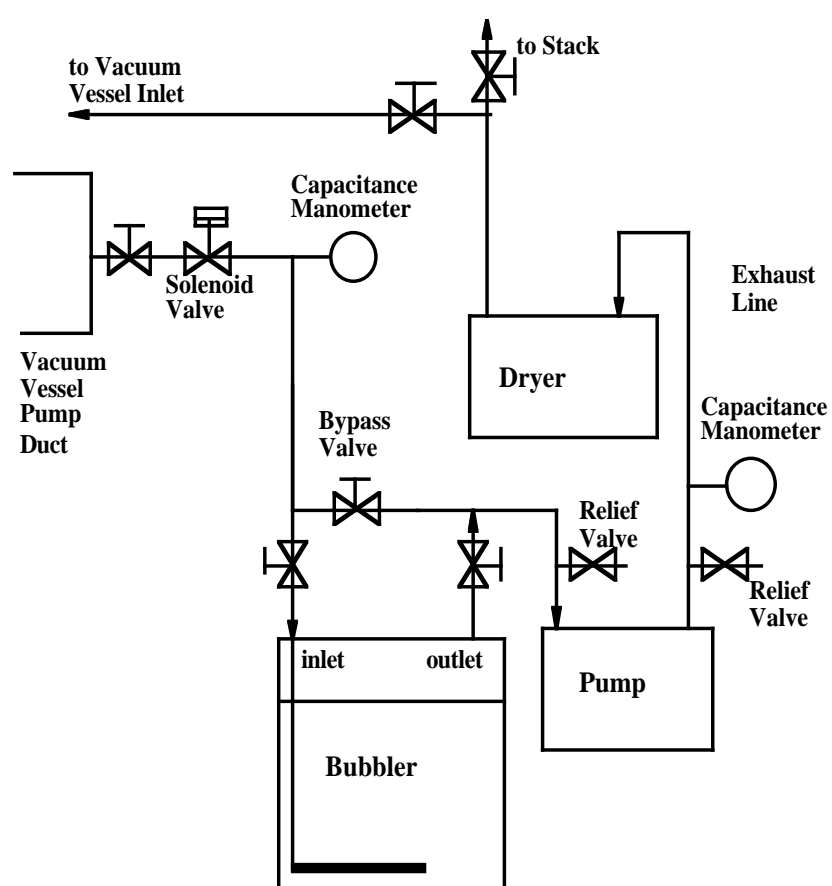

Fig. 2. Diagram of the main components of the Drum Bubbler System.

Safety considerations were an important part of the Drum Bubbler System design since it was expected to operate unattended on a continuous basis. Both the mechanical and electrical designs were thoroughly examined for failure modes in order to provide a very safe and reliable system. The 55 gallon drum is housed in a secondary containment vessel, a High Integrity Container (HIC), in order to preclude tritiated water from spilling onto the Test Cell floor in the event of a breach of the drum. The HIC also serves as the disposal container. A safety relief valve was installed at the inlet of the pump to prevent the drum from being pumped down to below its rated value. This safety relief valve was set to be fully open at a negative pressure of $10^{\prime \prime}$ $\mathrm{Hg}$. A check valve was installed in the bubbler inlet line to prevent the water from backing up into the vacuum vessel if the bubbler were to be inadvertently opened up to the torus while it was under vacuum. The exhaust line of the pump also has a pressure relief valve set to open at about 1250 Torr to prevent the line from being overpressurized should the vacuum vessel inlet valve close while operating in the closed loop configuration.

The bubbler system was installed with a motor controller center (MCC) which powers the pump, dryer, and the vacuum vessel inlet and outlet solenoid valves. The solenoid valves are normally closed valves that isolate the vacuum vessel when de-energized. The thermal overload circuits in the MCC were sized to protect against a mechanical seizure of the pump or a failure of the dryer compressor, both of which would be reflected as an electrical overload in the MCC. The response of the MCC to any overload is to trip open and de-energize the pump and dryer and isolate the vacuum vessel. The Drum Bubbler System is configured with three capacitance manometers with logic outputs connected to the MCC. These gauges are located on the vacuum vessel, in the bubbler inlet and in the pump exhaust lines. The bubbler inlet gauge is a backup to the pump inlet safety relief valve and is set to trip the MCC if the pressure in the bubbler drops to 465 Torr. The pump exhaust gauge is set to trip the MCC at 1150 Torr and the torus capacitance manometer will trip the MCC if the pressure in the vacuum vessel rises to 740 Torr. The HVAC stack and the Test Cell are both equipped with tritium monitors which are alarmed to notify laboratory personnel in the case of excessive tritium in either the stack or the Test Cell. Direct exhaust of a small amount of air from the vessel using the bypass mode of the Drum Bubbler System was used, along with grab sample measurements of the torus atmosphere, to determine the tritium level periodically. The tritium captured by the Drum Bubbler System was measured with analysis of water samples from the drum. These measurements demonstrated that $>90 \%$ of the tritium coming from the vessel was in the form of water vapor (HTO). The Drum Bubbler System has proved to be an effective and economical method for reducing the free tritium levels in the vacuum vessel. During the 1996 Outage the bubbler system was operated for about a thousand hours and removed approximately $100 \mathrm{Ci}$ from the vacuum vessel. At the time of the first port cover removal the free tritium was measured to be about $1 \mathrm{Ci}$. During the present safe shutdown phase of TFTR, the free tritium in the vacuum vessel has again leveled off at approximately $1 \mathrm{Ci}$.

\section{Variable Flow System}

While the purpose of the previously mentioned cleanup systems was to reduce the free tritium in the vacuum vessel in preparation for removing vessel port covers, the main consideration for the removal of the port covers became the minimization of the exposure of personnel to the tritiated atmosphere. This was accomplished by maintaining a negative pressure in the vacuum vessel relative to the Test Cell (between -1.5" and -0.05" w.c.) and ensuring an adequate flow of air into the torus through the port cover openings. Because the size of the port covers to be removed varied from approximately $1000 \mathrm{in}^{2}$ to $5 \mathrm{in}^{2}$, a system was designed that would maintain the desired negative pressure over a wide range of conditions. It was calculated that for openings of $1000 \mathrm{in}^{2}$, to maintain a face velocity of 225 FPM, the system would have to be capable of flowing in excess of $1500 \mathrm{cfm}$. At the other extreme were small port covers that were to be removed from the bottom of the vacuum vessel where fine graphite dust had accumulated from years of machine operation on the carbon limiters. When these port covers were removed it was essential that a low flow be maintained to minimize the inrush and turbulence of air and thus to prevent the carbon dust from becoming airborne. In this instance, a negative pressure of -0.05 inches w.c. was required. 
The Variable Flow System consisted of connecting the vacuum vessel to the Test Cell HVAC exhaust system via a damper using 12 inch diameter flexible hose. The Test Cell HVAC system, which is manifolded into a common header for the facility exhaust stack with a flow rate greater than $22,000 \mathrm{cfm}$, had a nominal flow rate of $12,000 \mathrm{cfm}$ during the 1996 Outage. In parallel with the 12 inch line, a 6 inch flexible line was also connected to the Test Cell HVAC system to service small port openings. Both manual and electronic differential gauges were installed in the system to monitor the differential pressure between the Test Cell and the vacuum vessel. The electronic system also monitored the flow rate of air drawn through the vacuum vessel and controlled the damper in the 12 inch system. A blast gate valve was controlled manually when the 6 inch system was used for the smaller port covers. Two different mechanical gauges were used to accurately measure the wide range of pressure differences. During port cover removal the Variable Flow System was continuously manned and monitored to ensure the proper negative pressure was maintained for the various sizes of openings in the vacuum vessel. For the small graphite dust coated windows the vessel was initially kept at -0.05 " w.c. while the window was removed and then the pressure difference was increased until a blankoff flange was installed. During the 1996 Outage this system was used during the removal of more than 60 port covers with the interior of the vacuum vessel open to the Test Cell for more than 50 hours.

\section{SUMMARY}

In preparing for the removal of port covers from the tokamak after years of DT operation, maintaining ALARA exposure to tritium was the primary concern. It was also important to accomplish these tasks in an efficient manner to reduce radiation exposure time and to minimize the resources required. As a result a three part system was developed to both reduce the free tritium in the vessel prior to port cover removal and for maintaining the appropriate influx of air into the torus during these activities. The first two systems were dedicated to the reduction of the free tritium in the vacuum vessel. Both of these systems were efficient and cost effective in their implementation. The first was a modest reconfiguration of the existing Torus Cleanup System and the second a relatively inexpensive drum bubbler system. The third system was a modification to the facility HVAC system to maintain regulated negative pressure in the vacuum vessel during the removal of various sized port covers. These systems were successful in maintaining personnel exposure ALARA when removing port covers during the 1996 Outage and we are again using these systems during the on-going shutdown phase of TFTR.

\section{ACKNOWLEDGMENTS}

The authors would like to thank the technicians from the machine operations, tritium, facilities and Health Physics groups at PPPL for their efforts on this project.

\section{REFERENCES}

[1] A. Nagy, et. al., "Tritium Recovery from the TFTR Vessel", Proceedings of $17^{\text {th }}$ IEEE Fusion Symposium

[2] M. Kalish, et. al., "Design Improvements and Lessons Learned for the TFTR Tritium Cleanup and Gas Holding Tank Sampling Systems", Proceedings of the $16^{\text {th }}$ IEEE/NPSS SOFE '95, Sept. 1995

[3] K. Rule, S. Larson, P. Kivler, J. Scott, "Portable Tritium Processing Using a Drum Bubbler", presented at the sixth All-Russian Conference on Engineering Problems of Thermonuclear Reactors, May, 1997, St. Petersburg, Russia 